Article

\title{
Investigation on High Temperature Rheological Behaviors and Fatigue Performance of Trans-Polyoctenamer-Activated Crumb Rubber Modified Asphalt Binder
}

\author{
Yan $\mathrm{Mu}^{1}$, Feng $\mathrm{Ma}^{1, *}$, Jiasheng Dai ${ }^{1, *} \mathbb{C}$, Chen $\mathrm{Li}^{1}$, Zhen $\mathrm{Fu}^{2}{ }^{2 *}$, Tiantian Yang ${ }^{1}$ and Meng Jia ${ }^{1}$ \\ 1 Key Laboratory Special Area Highway Engineering of Ministry of Education, Chang'an University, \\ Xi'an 710064, Shaanxi, China; my_bj_2008@126.com (Y.M.); 2018121140@chd.edu.cn (C.L.); \\ 2017221198@chd.edu.cn (T.Y.); mengjia@chd.edu.cn (M.J.) \\ 2 School of Material and Science Engineering, Chang'an University, Xi'an 710064, Shaanxi, China \\ * Correspondence: mafeng@chd.edu.cn (F.M.); daijiasheng@163.com (J.D.); zhenfu@chd.edu.cn (Z.F.); \\ Tel.: +86-029-8233-4823 (F.M.)
}

Received: 7 July 2020; Accepted: 5 August 2020; Published: 7 August 2020

\begin{abstract}
Asphalt binders have been modified with Crumb rubber (CR) as an effort to fulfil the demand for the development of eco-friendly and sustainable pavements. The objective of this study was to investigate the high temperature rheological behaviors and fatigue performance of crumb rubber modified asphalt (CRMA) binder activated using trans-polyoctenamer (TOR). Long-term and short-term aging tests were performed on samples by thin film oven test (TFOT) and pressure aging vessel (PAV). Rotational viscosity (RV), softening point, and dynamic shear rheometer (DSR) tests were conducted to characterize the rheological and physical performance. A linear amplitude sweep (LAS) test was employed to evaluate the fatigue performance. The results show that TOR-activated CRMA is more capable of hardening the matrix bitumen and improving its high-temperature viscoelastic properties after TFOT. The high temperature viscoelasticity is significantly better than styrene-butadiene-styrene block (SBS) modified asphalt (SBSMA) and CRMA. TOR-activated CRMA exhibits strong rutting resistance, but it is more likely to generate fatigue cracks under the violent advancement of complex modulus. Therefore, TOR active agent has a negative impact on the fatigue performance of CRMA. SBSMA exhibited superior fatigue resistance. The viscosity temperature index (VTS) of TOR-activated CRMA and CRMA was basically identical; the TOR did not significantly improve the temperature sensitivity of CRMA.
\end{abstract}

Keywords: crumb rubber modified bitumen; trans-polyoctenamer; high-temperature rheological behavior; rutting performance; fatigue performance; temperature sensibility

\section{Introduction}

In recent years, extreme weather has occurred frequently, which has a non-negligible impact on the life and performance of basic transportation facilities [1-3]. For purpose of improving the performance of bitumen pavements as one of the facilities, more and more polymers (styrene-butadiene-styrene block, styrene butadiene rubber, ethylene-vinyl acetate copolymer, polyethylene, etc.) have been researched as modifiers of asphalt binders and mixtures [4,5]. The use of crumb rubber (CR) in road engineering has attracted increasing attention in many areas. Crumb rubber modified asphalt (CRMA) binder has been proven to be capable of endowing matrix bitumen with excellent rutting resistance, fatigue resistance, among others [6-8]. It is also an effective method to reduce environmental pollution caused by the accumulation of abandoned car tires [9]. Furthermore, compared to the bitumen modified 
with SBS, which is the most popular thermoplastic elastomer, CRMA can reduce construction costs as an aggregate adhesive [10]. CR contributes to layer endurance during its service life. Therefore, reclaimed asphalt pavement (RAP) binder is often used with CRMA to make up for the adverse effects of RAP binder on the fatigue performance of mixtures [11,12]. Therefore, numerous studies have been carried out on the content of $\mathrm{CR}$, the way of addition, the improvement mechanism and the performance of CRMA $[13,14]$.

However, anti-aging and fatigue performance of CRMA at high temperature have not been solved well so far. Aging of bitumen can be divided two stages: short-term and long-term aging [15]. The former mainly happens during the manufacturing process of mixing and changes the properties of bitumen as well as the performance of bitumen pavement. The latter occurs during the service life of the pavement and is the further oxidation of light components, which results from the environmental conditions [16,17]. Aging is not an avoidable process in bitumen paving and influences the performance of CRMA significantly, such as cracking, stripping and potholes [18]. Otherwise, CR degradation and aging seriously affect the quality and life of CR modified bitumen pavement. Cui et al. [19] found that the low-temperature cracking and deformation resistance of CRMA are seriously affected by heat aging. Owing to differences in molecular structure, the polarity and solubility of rubber and bitumen can degrade all aspects of CRMA performance [20].

Scholars at present tend to use additives i.e., bio-oil, organic montmorillonite, among others to apply the composite modification to CRMA to overcome the drawbacks of ageing and storage stability [21,22]; however, these kinds of additives only improve the performance of CRMA at the physical level, and the improvement of CRMA performance is not ideal. Therefore, CR can be modified and activated by adding a reactive additive such as a crosslinking agent, and can also be added by adding polyphosphoric acid and a polymer compatibilizer having an unsaturated bond, improving the compatibility of CR and bitumen [23,24]. Trans-polyoctenamer (TOR) is a high molecular polymer additive with many unsaturated bonds in the molecule and high reactivity [25]. The chemical structure of TOR is listed in Figure 1. TOR is a polymer composed of linear and cyclic macromolecules. The double bond in the structure undergoes a cross-linking reaction with the sulfur component on the surface of CR [26]. Figure 2 shows the reaction mechanism of TOR vulcanization. The cross-linking reaction between sulphur and polyoctenamer is anticipated to mainly occur at the carbon-carbon double bonds $(C=C)$. Due to the addition of TOR linker in $C R$ and matrix bitumen, new molecules are synthesized, which are complex in composition and have large changes in properties [27]. Some studies found that the addition of the activator TOR to the CRMA has outstanding effects on pavement anti-cracking, waterproof, sound insulation and noise reduction $[28,29]$. In addition, the preparation process is easy and flexible, construction workability and heat storage stability are good, and it is suitable for various types of bitumen pavement maintenance engineering [29].

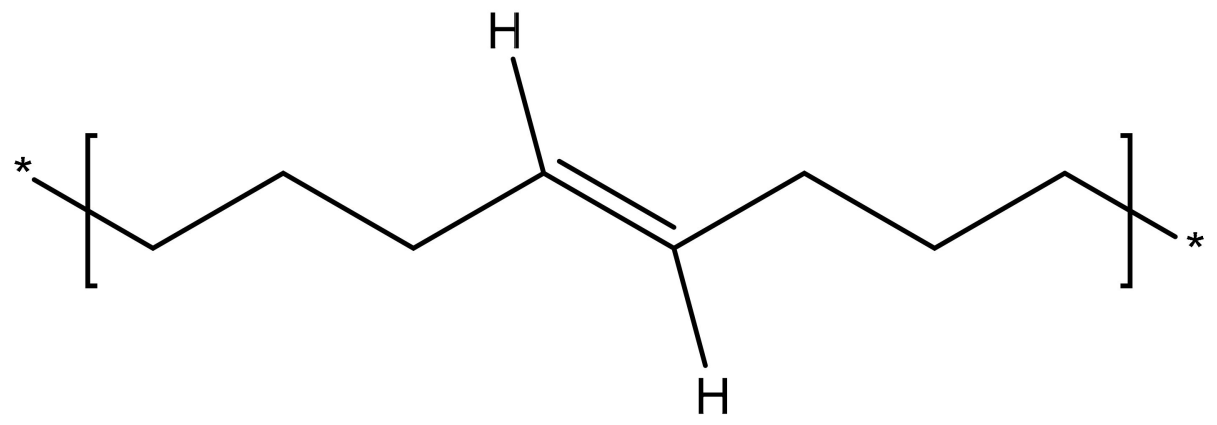

Figure 1. Chemical structure of trans-polyoctenamer (TOR). 


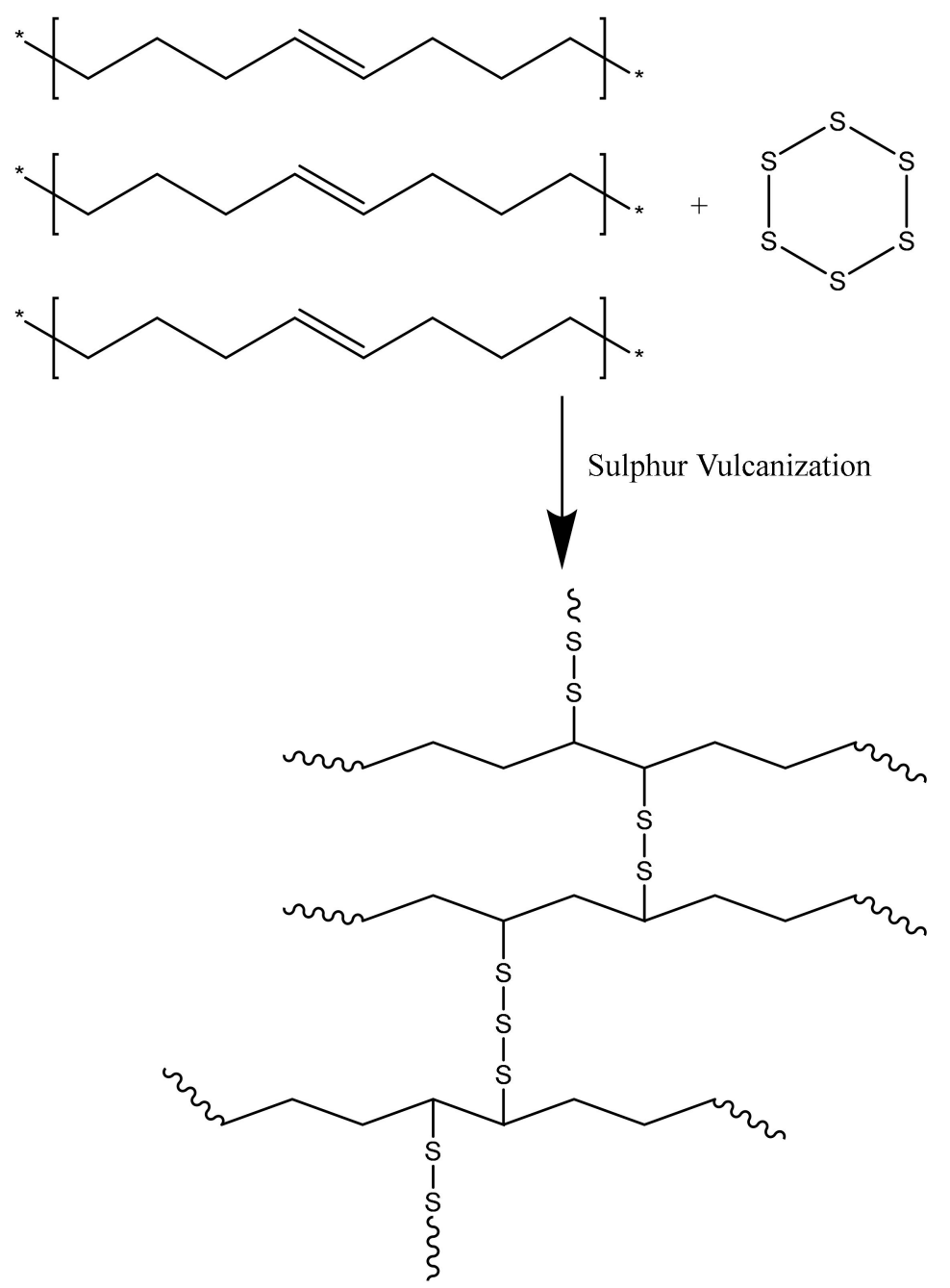

Figure 2. Reaction mechanism of vulcanization of TOR.

The research on TOR-activated CRMA is very limited. Peng et al. [28] found that the shear modulus of bitumen increases and the phase angle decreases after adding TOR. In fact, TOR can promote compatibility between $\mathrm{CR}$ and matrix bitumen, and increases the high-temperature rutting resistance of bitumen. Liu et al. [30] showed that there is a complex chemical reaction between TOR and CRMA, which changes the rheology of CRAM and contributes to the storage stability of asphalt binders. Liang et al. $[27,31]$ indicated that the double bond in TOR participates in chemical reactions and is beneficial to stability, improving CRMA compatibility and storage stability. CR activated by TOR reduces the content of polycyclic aromatic hydro-carbons (PAHs) and sulfur compounds, which means that the toxicological potential of smoke is low. Ma et al. [32] proved that TOR-activated crumb rubber asphalt mixture prepared by the dry method can obtain excellent road performance i.e., better rutting resistance, low temperature cracking resistance, and water stability. However, the effect of aging on TOR additives at high temperature rheological property and fatigue property of CRMA has not been clearly understood.

In this work, trans-polyoctenamer (TOR) is used to activate CRMA. The thin film oven test (TFOT) and pressure aging vessel (PAV) are used to simulate short-term and long-term aging of different bitumen samples. The physical properties of asphalt binders are analyzed using the softening point and the Brookfield rotational viscosity. The rheological behaviors were systematically analyzed using a dynamic shear rheometer (DSR). Seven indicators, including storage modulus $\left(G^{\prime}\right)$, loss modulus $\left(G^{\prime \prime}\right)$, shear modulus $\left(\left|G^{*}\right|\right)$, phase angle $(\delta)$, rutting factor $\left(\left|G^{*}\right| / \sin \delta\right)$, fatigue factor $\left(\left|G^{*}\right| \times \sin \delta\right)$ in the frequency/temperature sweep test, fatigue life $\left(N_{f}\right)$ in linear amplitude sweep, are applied to 
systematically describe the high-temperature rheological properties of asphalt binders in different aging states. The viscoelastic behavior, rutting resistance, temperature sensitivity and fatigue resistance of the modified asphalt binder are thoroughly investigated. Finally, the analysis and results are discussed, and some recommendations are given.

\section{Materials and Experimental}

\subsection{Materials}

Technical properties of matrix bitumen, Karamay 110 (KLM110), were evaluated by following Chinese standard "Standard Test Methods of Bitumen and Bituminous Mixtures for Highway EngineerinG" (JTJ E20-2011). The test results are listed in Table 1. The crumb rubber (CR) was supplied by ZhongNeng Rubber Co. Ltd. Chengdu, Sichuan, China. The particle diameter of crumb rubber ranges from 0.250 to $0.425 \mathrm{~mm}$. TOR additive is supplied by EVONIK Company (Essen, Germany). The properties of CR and TOR-activated crumb rubber are listed in Table 2.

Table 1. Matrix bitumen properties.

\begin{tabular}{ccc}
\hline Items & Measured Values & Specified Values \\
\hline Penetration $\left(25^{\circ} \mathrm{C}, 0.1 \mathrm{~mm}\right)$ & 111 & $100 \sim 120$ \\
Ductility $\left(15^{\circ} \mathrm{C} / 10^{\circ} \mathrm{C}, \mathrm{cm}\right)$ & $>150$ & $\geq 60 / \geq 40$ \\
Softening point $\left({ }^{\circ} \mathrm{C}\right)$ & 45.8 & $\geq 43$ \\
\hline
\end{tabular}

Table 2. Properties of crumb rubber (CR) and TOR-activated crumb rubber.

\begin{tabular}{cccccc}
\hline \multirow{2}{*}{ Project } & $\begin{array}{c}\text { Relative } \\
\text { Density }\end{array}$ & $\begin{array}{c}\text { Moisture } \\
\mathbf{( \% )}\end{array}$ & $\begin{array}{c}\text { Metal Content } \\
\mathbf{( \% )}\end{array}$ & $\begin{array}{c}\text { Fiber Content } \\
\mathbf{( \% )}\end{array}$ \\
\hline \multicolumn{2}{c}{ Technical indicators } & - & $<1.0$ & $<0.01$ & $<1.0$ \\
Test results & $\begin{array}{c}\text { Crumb rubber } \\
\text { TOR-activated } \\
\text { crumb rubber }\end{array}$ & 1.15 & 0.4 & 0.007 & 0.002 \\
& 1.21 & 0.53 & 0.004 & 0.003 \\
\hline
\end{tabular}

\subsection{Preparation TOR-Activated CR and Various Modified Asphalt Binders}

The relevant literature we refer to shows that when the content of SBS modifier is about $4.5 \%$, the performance of SBS modified asphalt binder is the best $[9,33]$. SBS modified asphalt binder is currently the most used asphalt binder in road engineering. At the same time, the optimal blending amount of crumb rubber modified asphalt binder is about $20 \%[30,34,35]$. Therefore, we choose $4.5 \%$ of SBS and $20 \%$ of crumb rubber, which will be used as a comparison and reference.

First of all, new crumb rubber material made up of 40-mesh crumb rubber, TOR coupling agent, and some other materials. The various CRMA were prepared in a high-speed mixer by wet method. The matrix bitumen is heated to $175^{\circ} \mathrm{C}$. Three different bitumen modifiers $(20 \%$ of crumb rubber, $20 \%$ of TOR-activated crumb rubber, $4.5 \%$ of SBS) were added into the matrix bitumen at $175^{\circ} \mathrm{C}$ and were sheared at $4000 \mathrm{rpm}$ for $1 \mathrm{~h}$. Finally, the mixtures were placed in a stirrer at $175^{\circ} \mathrm{C}$ for $1 \mathrm{~h}$. For easy checking, the asphalt binders with CR, TOR-activated CR and SBS were abbreviated as CRMA, TOR-activated CRMA and SBSMA, respectively.

\subsection{Test Methods}

\subsubsection{Ageing Procedure}

Oxidative ageing of modified asphalt binders was performed using the thin film oven test, TFOT (ASTM D1754), and pressurized ageing vessel, PAV (ASTM D6521). PAV aging procedure at $100{ }^{\circ} \mathrm{C}$ and $2.1 \mathrm{MPa}$ for $20 \mathrm{~h}$ was used for long-term aging simulation. In the TFOT, bitumen was placed in an oven at $163{ }^{\circ} \mathrm{C}$ for $5 \mathrm{~h}$. TFOT simulates short-term ageing that occurs during asphalt 
mixing and pavement construction, while PAV simulates long-term ageing that takes place during the service process of asphalt pavement.

\subsubsection{Physical Properties Test}

The softening point and the Brookfield rotational viscosity of various asphalt binders were tested according to Chinese standards "Standard Test Methods of Bitumen and Bituminous Mixtures for Highway EngineerinG" (JTJ E20-2011). The Brookfield rotational viscosity was carried out at $135^{\circ} \mathrm{C}$ and $175^{\circ} \mathrm{C}$ with a shear rate of $20 \mathrm{rpm}$. Three replicates were used in the softening point and the Brookfield rotational tests.

\subsubsection{Dynamic Shear Rheometer Test}

In this study, three kinds of rheological tests were chosen. The frequency sweep test and the temperature sweep test were the conventional DSR tests to characterize the rheological properties of asphalt binders. The asphalt binders tested were unaged, TFOT-aged binder and PAV-aged binder. The DSR (DHR-1, TA Instruments, New Castle, DE, USA) was used to apply a shear stress on a thin asphalt binder specimen sandwiched between two parallel oscillatory plates (diameter of $25 \mathrm{~mm}$ or $8 \mathrm{~mm}$ ) with a gap of $1 \mathrm{~mm}$ or $2 \mathrm{~mm}$. Two replicates were used in the DSR test.

The temperature sweep was performed at a constant strain of $1 \%$ and a constant frequency of $10 \mathrm{rad} / \mathrm{s}$ with temperature ranging $46-78{ }^{\circ} \mathrm{C}$ in intervals of $4{ }^{\circ} \mathrm{C}$. The frequency sweep test was tested at different temperatures $\left(40,50,60,70\right.$ and $\left.80^{\circ} \mathrm{C}\right)$ in the frequency range of 0.1 to $100 \mathrm{rad} / \mathrm{s}$. The strain was maintained at $2 \%$. Three indicators, shear modulus $\left(\left|G^{*}\right|\right)$, phase angle $(\delta)$ and rutting factor $\left(\left|G^{*}\right| / \sin \delta\right)$, were automatically calculated, respectively. The unaged and TFOT-aged asphalt binder was a $1 \mathrm{~mm}$ diameter plate with a gap between $25 \mathrm{~mm}$ parallel plates. When PAV-aged asphalt binders were used, the corresponding values were $8 \mathrm{~mm}$ and $2 \mathrm{~mm}$, respectively. The storage modulus $\left(\mathrm{G}^{\prime}\right)$ and loss modulus $\left(G^{\prime \prime}\right)$ in the frequency sweep test were used to evaluate the viscoelastic behavior. The rutting resistance was characterized by shear modulus $\left(\left|G^{*}\right|\right)$, phase angle $(\delta)$, rutting factor $\left(\left|G^{*}\right| / \sin \delta\right)$ in the frequency sweep test. The viscosity temperature index (VTS) was used to evaluate temperature sensitivity. It can be calculated by shear modulus $\left(\left|G^{*}\right|\right)$, phase angle $(\delta)$ in the temperature sweep test.

Linear amplitude sweep (LAS) was utilized to characterize the resistance of an asphalt binder to fatigue damage. LAS testing of PAV-aged asphalt binder was carried out at $25^{\circ} \mathrm{C}$ using standard AASHTO TP101-14. According to LAS test results, the correlation between the applied shear strain and the fatigue life of the asphalt binder can be analyzed using the viscoelastic continuous medium damage (VECD) theory [36-38]. Finally, the fatigue life $N_{f}$ could be predicted, as shown in Equation (1):

$$
N_{f}=A_{35}\left(\gamma_{\max }\right)^{-B}
$$

where $A_{35}$ and $B$ are the viscoelastic continuum damage (VECD) coefficients.

\section{Results and Discussion}

\subsection{Viscoelastic Behavior}

The softening point and the viscosity of four samples were listed in Figures 3 and 4, respectively. To further investigate the viscoelasticity of TOR-activated CRMA viscoelastic parameters (storage modulus $G^{\prime}$, loss modulus $\left.G^{\prime \prime}\right)$ in the linear viscoelastic range were obtained from the DSR. Therefore, frequency sweeps were performed on all unaged, TFOT-aged and PAV-aged asphalt binders. Figures 5 and 6 show the changes in $G^{\prime}$ and $G^{\prime \prime}$ of different unaged and aged asphalts as a function of frequency. 


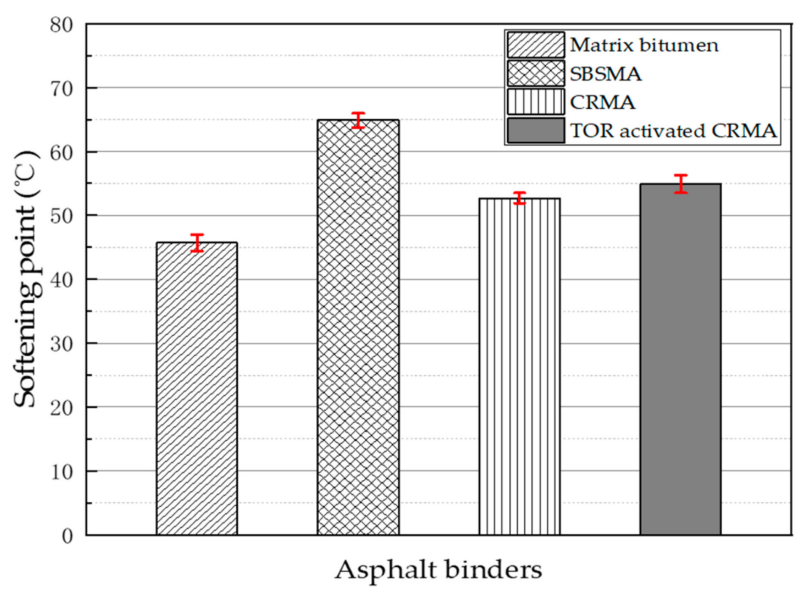

Figure 3. Softening point of four binders on unaged asphalts.

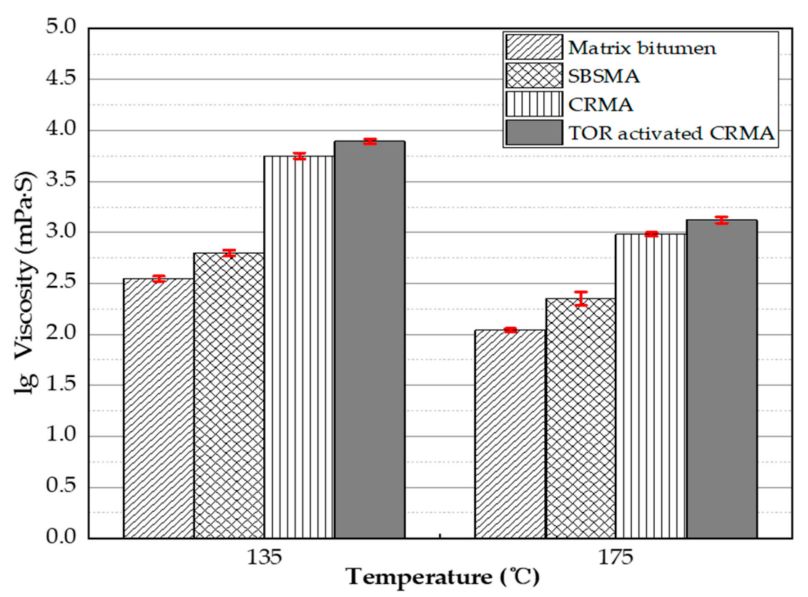

Figure 4. Viscosity of four binders on unaged asphalts.

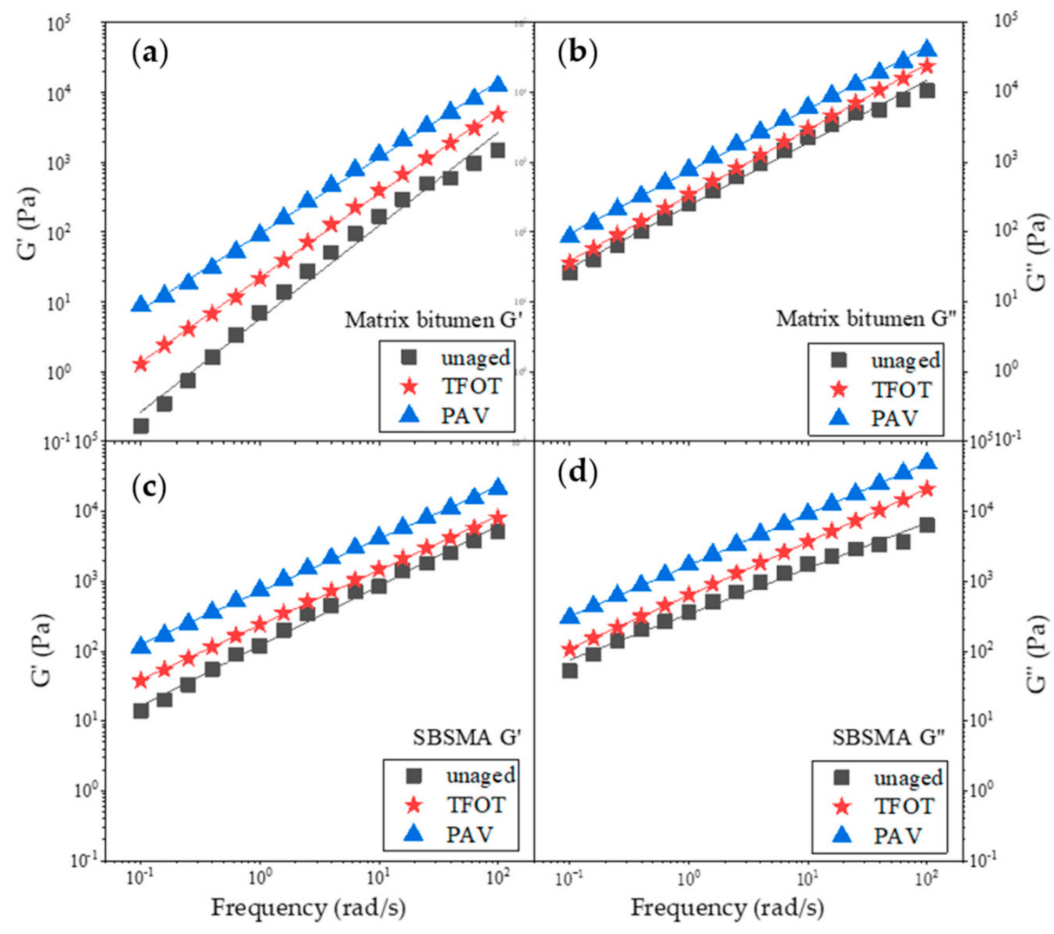

Figure 5. Viscoelastic parameters versus frequency of unaged and aged matrix bitumen and SBSMA at $60^{\circ} \mathrm{C}$. (a) Matrix bitumen $\mathrm{G}^{\prime}$; (b) Matrix bitumen G"; (c) SBSMA G'; (d) SBSMA G". 


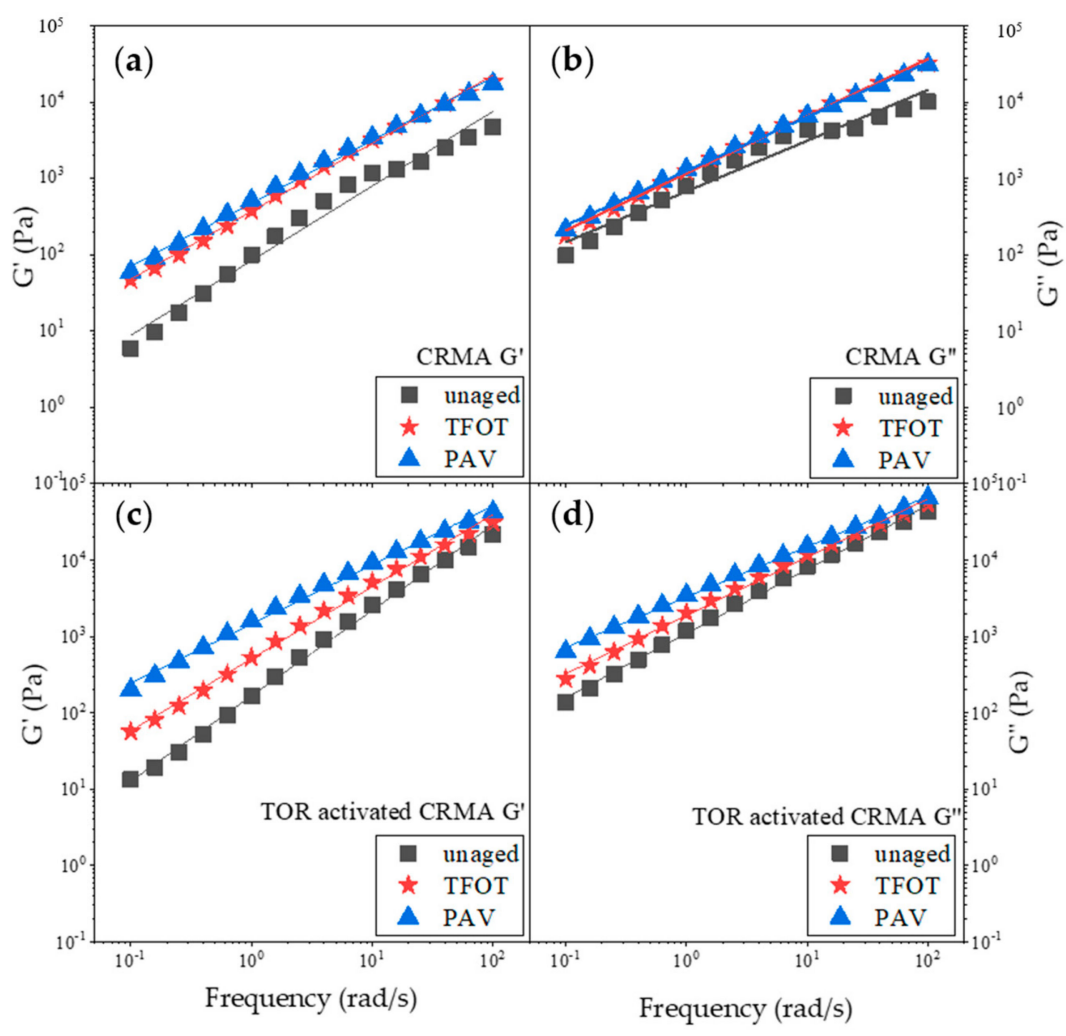

Figure 6. Viscoelastic parameters versus frequency of unaged and aged crumb rubber modified asphalt (CRMA) and TOR-activated CRMA at $60^{\circ} \mathrm{C}$. (a) CRMA G'; (b) CRMA G"; (c) TOR activated CRMA G'; (d) TOR activated CRMA G".

Figure 3 shows that the softening point of modified asphalt binders elevates obviously compared with matrix bitumen. TOR additive had a greater effect on the softening point of TOR-activated CRMA, although the improvement of CRMA activated by TOR is lower than that of SBSMA. It can be seen from Figure 4 that the viscosity of the four samples decreases with increasing temperature. The viscosity of TOR-activated CRMA was greater than that of other asphalt binders under the same temperature, and the mechanism of TOR was involved in the advance of viscosity.

It can be seen from the Figure 6 that as frequency decreases, the difference of $G^{\prime}$ and $G^{\prime \prime}$ gradually increases. In addition, in the high temperature and low frequency range, $G^{\prime}$ fell faster than $G^{\prime \prime}$, which was predicting the main viscous behavior at low frequencies and $60{ }^{\circ} \mathrm{C}$. However, the elastic properties of TFOT and PAV-aged modified asphalt binder were significantly distinct compared to unaged asphalt binder. The distinctions were also obvious for asphalt binder with TOR. For unaged samples, the modified asphalt binder had a larger $\mathrm{G}^{\prime}$ value in the selected frequency range. For unaged TOR-activated CRMA, G' was significantly larger than SBSMA and CRMA.

The $G^{\prime}$ and $G^{\prime \prime}$ after TFOT and PAV aging increased significantly, especially PAV aging, indicating an improvement in mechanical properties. However, $G^{\prime \prime}$ of various asphalt binders after aging had a different extent of increase. It can be inferred from the gap between TFOT and PAV that the increase in matrix bitumen is most pronounced in terms of viscoelastic parameters compared to unaged samples. The change in CRMA viscoelastic parameters after PAV long-term aging was minimal. TOR-activated CRMA exhibited a maximum of $\mathrm{G}^{\prime}$ and $\mathrm{G}^{\prime \prime}$ after TFOT and PAV aging compared to other asphalt binders. Aging will harden the bitumen, and the hardening effect will increase its stiffness, which will lead to asphalt binder embrittlement. This hardening effect will affect the ability to relax the stress. Adding TOR to asphalt binder may decrease the effect of the aging process.

The corresponding relationship between the angular frequency $\omega$ and the viscoelastic factor can be a rough analysis of the phase structure of the asphalt binder. The change of internal phase structure for viscoelastic bitumen materials can significantly affect viscoelastic parameters. Scientists believed 
that the gap between bridging microscale structures and macroscale features can be connected by linear viscoelasticity [39]. It means viscoelastic parameters can measure the difference of modifiers on micro-scale structures of asphalt binder. In the low frequency region, $G^{\prime}, G^{\prime \prime}$ and the angular frequency $\omega$ of the homogeneous polymer in this test had the following relationship: the slope of $\lg G^{\prime \prime}(\omega)-\lg \omega$ was 1 . The slope of $\lg G^{\prime}(\omega) \lg \omega$ was 2 . The slope of the multiphase polymer was smaller than these two values. Related literature studies have shown that the degree of heterogeneity of the material can be reflected by the degree of deviation of the slope of the low frequency region from the slope of the line viscoelastic relationship [40,41].

Figure 7 shows that the slopes of $G^{\prime}$ and $G^{\prime \prime}$ were relative to the angular frequency of various asphalt binders at $60^{\circ} \mathrm{C}$. The slope of $\lg \mathrm{G}^{\prime}(\omega)$ and $\lg \mathrm{G}^{\prime \prime}(\omega)$ for the $\lg w$ were less than 2 and 1 , respectively, indicating that the four samples are all heterogeneous systems. The degree of deviation was, however, different. For unaged samples, it can be obtained from Figure 7 that the degree of heterogeneousness is: SBSMA > CRMA > TOR-activated CRMA activator > matrix bitumen. The CRMA and the TOR-activated CRMA were compared separately. The former had a negative degree of homogeneity, because there will be surface hardening, desulfurization and the like, which is not conducive to fuse between the CR and the asphalt binder. For TOR-activated CRMA, TOR alleviated the compatibility of CR with matrix bitumen. The slope values of TOR-activated CRMA were greater than those of CRMA; however, with the deepening aging, the degree of heterogeneousness of TOR-activated CRMA became the biggest, which means more light components lessened, corresponding to the weakest aging resistance.

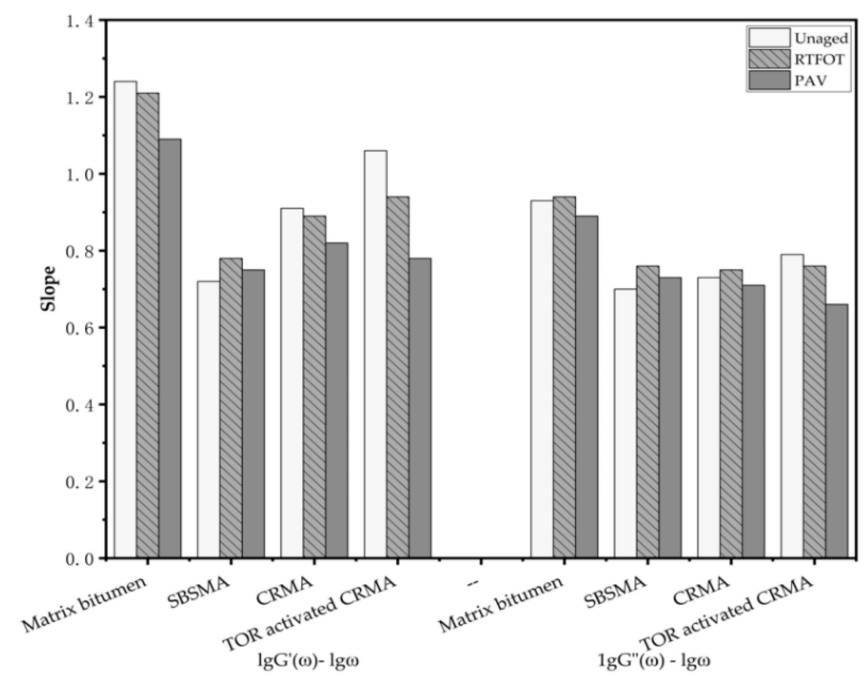

Figure 7. The slopes of $\lg \mathrm{G}^{\prime}(\omega)-\lg \omega, 1 \mathrm{~g} \mathrm{G} \mathrm{G}^{\prime \prime}(\omega)-\lg \omega$ of different asphalt binders at $60^{\circ} \mathrm{C}$.

\subsection{Rutting Resistance}

Figure 8 presents the phase angle and shear modulus of the four samples, after aging at $60{ }^{\circ} \mathrm{C}$, varying with frequency.

As shown in Figure 8, the value of $\left|\mathrm{G}^{*}\right|$ increases with increasing frequency and has an almost parallel upward curve, indicating that $\log \left|\mathrm{G}^{*}\right|$ and $\log \omega$ have a good linear correlation over the selected frequency range. After TFOT aging, CRMA spiked with TOR exhibited the highest value of $\left|G^{*}\right|$ while matrix bitumen exhibited a minimum of $\left|G^{*}\right|$. The $\left|G^{*}\right|$ of SBSMA was less than CRMA and TOR-activated CRMA. Similar behavior of various asphalt binders was observed during the PAV aging phase compared to the TFOT aging phase. However, the $\left|G^{*}\right|$ values of the TFOT-aged asphalt binder samples were lower than those of the other samples, which indicated that the asphalt binder becomes harder after long-term aging. The rutting resistance of TOR-activated CRMA after aging is better than those of the other three asphalt binders. However, compared with TFOT aging, TOR-activated CRMA after PAV aging has better anti-rutting performance. 

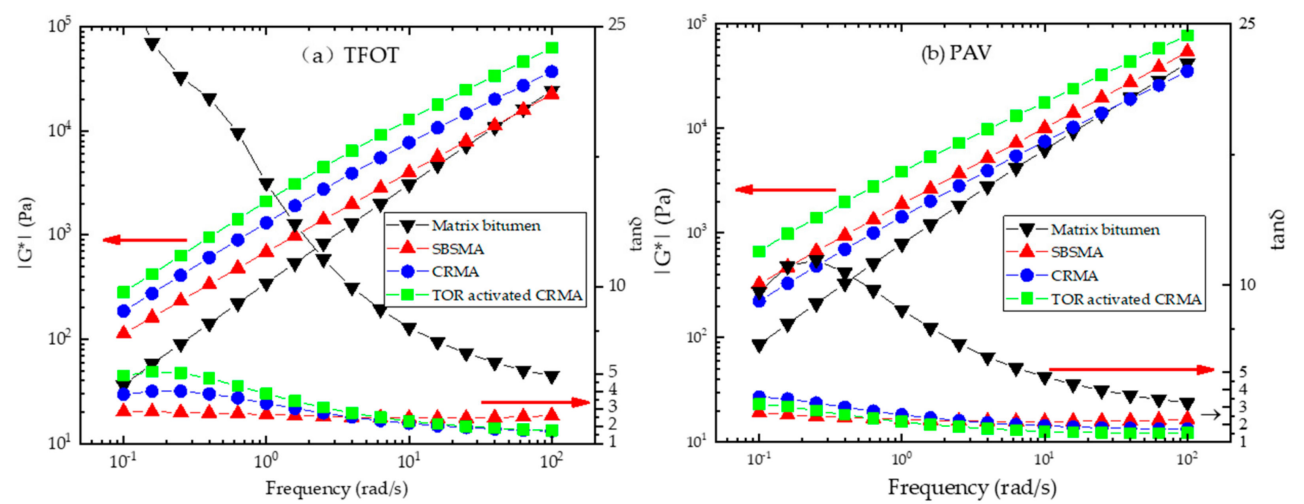

Figure 8. Changes in phase angle and shear modulus of asphalt binders in pace with frequency after (a) thin film oven test (TFOT) and (b) pressure aging vessel (PAV) aging at $60{ }^{\circ} \mathrm{C}$.

The phase angle is illustrated in $\tan \delta$ in Figure 8. Tan $\delta$ is identified as the ratio of $G^{\prime \prime}$ to $G^{\prime}$, which presented a balance of viscous/elastic performance. Higher $\tan \delta$ values indicated that the bitumen material exhibited more viscous behavior. According to the survey, in the frequency range studied and at $60{ }^{\circ} \mathrm{C}$, the tan $\delta$ of all asphalt binders was always $>1$, which means the main viscous behavior. The $\tan \delta$ of matrix bitumen showed a sharp decrease. On the contrary, SBSMA showed a substantially unchanged $\tan \delta$ in the low and high frequency range. The $\tan \delta$ of CRMA and TOR-activated CRMA decreased rapidly in the low frequency region, and decreased slightly in the high frequency range.

The rutting factor $\left(\left|G^{*}\right| / \sin \delta\right)$ can be used to evaluate the effect of different modifiers on the performance of bitumen materials at high temperatures. The higher the rutting factor, the better the performance of the bitumen material at high temperatures. Through the DSR test, $\left|G^{*}\right|$ and $\delta$ can be obtained intuitively, so that the rutting factor $\left(\left|G^{*}\right| / \sin \delta\right)$ can be calculated. The rutting factors of the four samples before and after aging are exemplified in Figure 9.
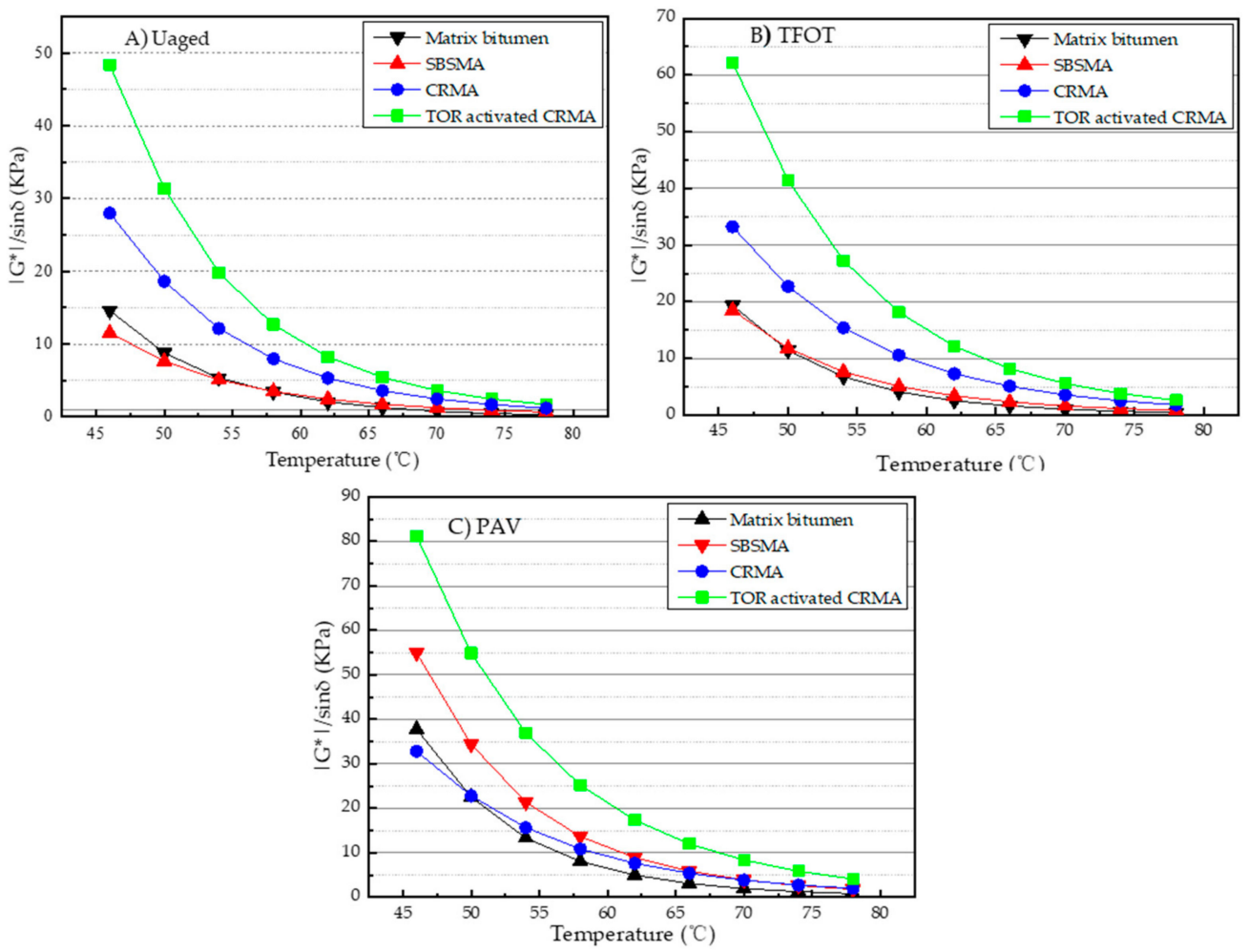

Figure 9. The $\left|G^{*}\right| / \sin \delta$ of four samples before and after aging. (A) Unaged; (B) after TFOT; (C) after PAV. 
Figure 9 shows that the rutting factor of four samples drops sharply with increasing temperature and then slowly decreases after a certain temperature. The rutting factor of TOR-activated CRMA was the largest. Therefore, under the same temperature conditions, the four asphalt binders had the best rutting resistance, followed by CRMA. However, compared with CRMA and TOR-activated CRMA, the increased degree of rutting factor of SBSMA was not extremely obvious, even smaller than the matrix bitumen when the temperature was lower than $55^{\circ} \mathrm{C}$.

The aging of the binder mainly consisted of two parts, volatilization and oxidation. Especially for the matrix bitumen (KLM110) with a large number of light components, the performance change of the modified asphalt binder occurring in the aging process was not negligible. Figure $9 \mathrm{~B}$ shows that after short-term aging, the rutting factor of all samples decreased with increasing temperature and decreased slowly after a certain temperature. After TFOT aging, the rutting factors of all asphalt binders were significantly increased. In addition, it indicated that the viscous component of bitumen increased sharply with increasing temperature, while the elastic component gradually decreased. At the same temperature, TOR-activated CRMA was more resistant to rutting than other binders were.

Similarly, TOR-activated CRMA exhibited the best rutting resistance among four asphalt binders at the same temperature after PAV aging from Figure 9C. Moreover, the SBSMA anti-rutting performance was significantly improved. Compared with the unaged SBSMA, the SBSMA after PAV aging had the most significant increase in the rutting factor in the test temperature range. The change in CRMA rutting factor after PAV aging was small. Whether it was the original sample, long-term aging, or short-term aging, the maximum $\left|\mathrm{G}^{*}\right| / \sin \delta$ of CRMA containing the TOR activator exhibited its preferred resistance to rutting.

\subsection{Temperature Sensitivity}

For areas with variable climates and large temperature differences, it is important to evaluate the temperature sensitivity of asphalt binder. The viscosity temperature index (VTS) is used to measure the temperature sensitivity of bitumen materials. VTS is calculated as follows:

$$
V T S=\frac{\lg \left(\lg \eta_{T 2}-\lg \eta_{T 1}\right)}{\lg T 2-\lg T 1}
$$

where $T 1$ and $T 2$ represent the temperatures of the two points (the temperature range in the temperature sweep), respectively, and $\eta_{T I}$ and $\eta_{T 2}$ respectively, represent the dynamic viscosity.

The viscosity $\eta^{*}$ can be calculated as follows:

$$
\eta^{*}=\frac{G^{*}}{\omega}
$$

where $\eta^{*}$ is the complex viscosity, $\left|G^{*}\right|$ is the complex modulus, and $\omega$ is the angular frequency. This formula has a prerequisite: the material should be Newtonian fluid. The asphalt binder is not a complete Newtonian fluid, so the coefficient correction is required. According to the Cox-Merz dynamic and static viscosity conversion rules, with a phase angle of less than $90^{\circ}$ and a lower temperature, Equation (3) is amended as:

$$
\eta^{\prime}=\frac{(\sin \delta)^{-4.8628}\left|G^{*}\right|}{\omega}
$$

where $\delta$ is the phase angle $\left(^{\circ}\right)$.

Figure 10 displays the VTS values of the four samples before and after aging. VTS values were sorted from large to small for unaged samples: matrix bitumen $>C R M A \approx$ TOR-activated CRMA $>$ SBSMA. The VTS value of matrix bitumen was the largest, which indicated that it had the largest rate of change with temperature and was most sensitive to temperature changes. It can be seen that the addition of modifier can significantly improve the temperature sensitivity of asphalt binder. 
Figure 10 shows that the VTS of CRMA and TOR-activated CRMA decreased after short-term aging followed by long-term aging. During the aging process, after the two reactions of volatilization and oxidation, the light components inside the binder are reduced, and heavier components such as asphaltenes and gums are increased. The sensitivity to temperature was correspondingly reduced. The SBSMA showed significant changes in this test. After short-term aging, its sensitivity showed an upward trend. The softening point of SBSMA after short-term aging was also inconsistent with the other asphalt binder, which is speculated to be due to the degradation of SBS. With the completion of SBS degradation, the SBSMA also showed a trend of reducing sensitivity after long-term aging. The VTS of TOR-activated CRMA and CRMA was basically identical, so the TOR did not significantly improve the temperature sensitivity of CRMA.

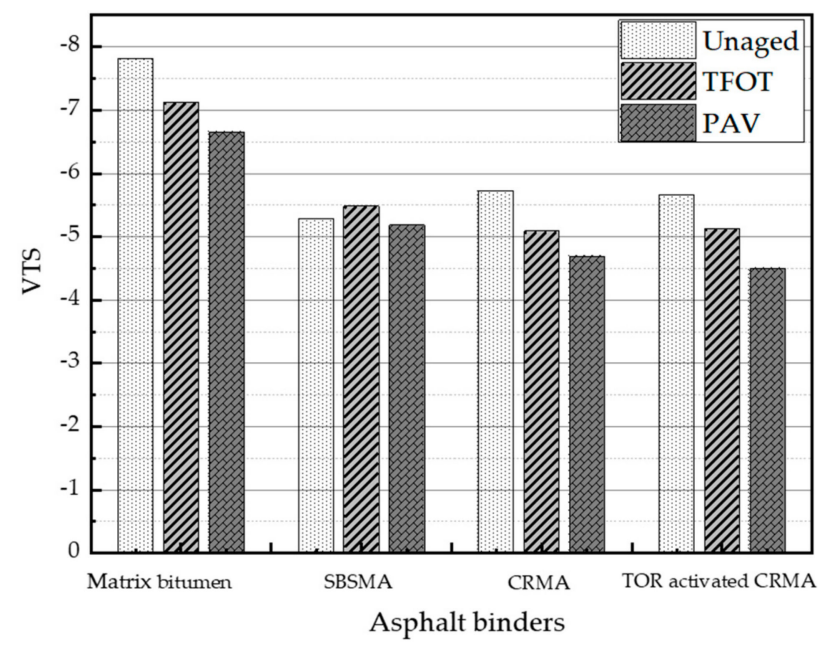

Figure 10. The viscosity temperature index (VTS) of four samples in different states.

\subsection{Fatigue Resistance}

Similarity to the anti-rutting theory of asphalt binder, SHRP believed that road surface fatigue cracking was also related to the content of elastic and viscous components, and that asphalt binder containing more viscous components can be beneficial to resisting fatigue cracking. Therefore, SHRP recommended that the fatigue factor $\left(\left|G^{*}\right| \times \sin \delta\right)$ can be used to characterize the fatigue resistance of bitumen materials at moderate temperatures. The increase in the rutting factor of bitumen materials can increase its ability to resist high temperature permanent deformation; however, the excessive rutting factors were more prone to cracking diseases at moderate and low isothermal temperatures.

Therefore, the fatigue factor can characterize the fatigue crack resistance of the asphalt binders after aging. The fatigue factors for asphalt binder samples are exemplified in Figure 11. Figure 11 shows that the fatigue factor of asphalt binder samples dropped rapidly with the increasing procedure of temperature. The fatigue life $N_{f}$ test results are shown in Figure 12.

Figure 11 shows that the fatigue factor of asphalt binder samples dropped rapidly with the increasing procedure of temperature. Whether it was short-term aging or long-term, TOR-activated CRMA had the highest fatigue factor, indicating that its fatigue resistance under different temperatures was the worst compared with the other three asphalt binders at high-temperature conditions. In contrast, SBSMA had a minor fatigue factor, illustrating that the fatigue resistance of SBSMA is better than that of CRMA and TOR-activated CRMA.

The LAS test was utilized to further study the fatigue performance of TOR-activated CRMA at moderate temperatures. Figure 12 shows the fatigue life results of the four samples at $2 \%$ and $4 \%$ strain levels. SBSMA shows the longest fatigue life span compared to other asphalt binders of the same strain level. Compared with matrix bitumen, the fatigue life of CRMA and TOR-activated CRMA are decreased. TOR-activated CRMA has a negative impact on the fatigue resistance of CRMA, which is the same as that expressed by the fatigue factor. 

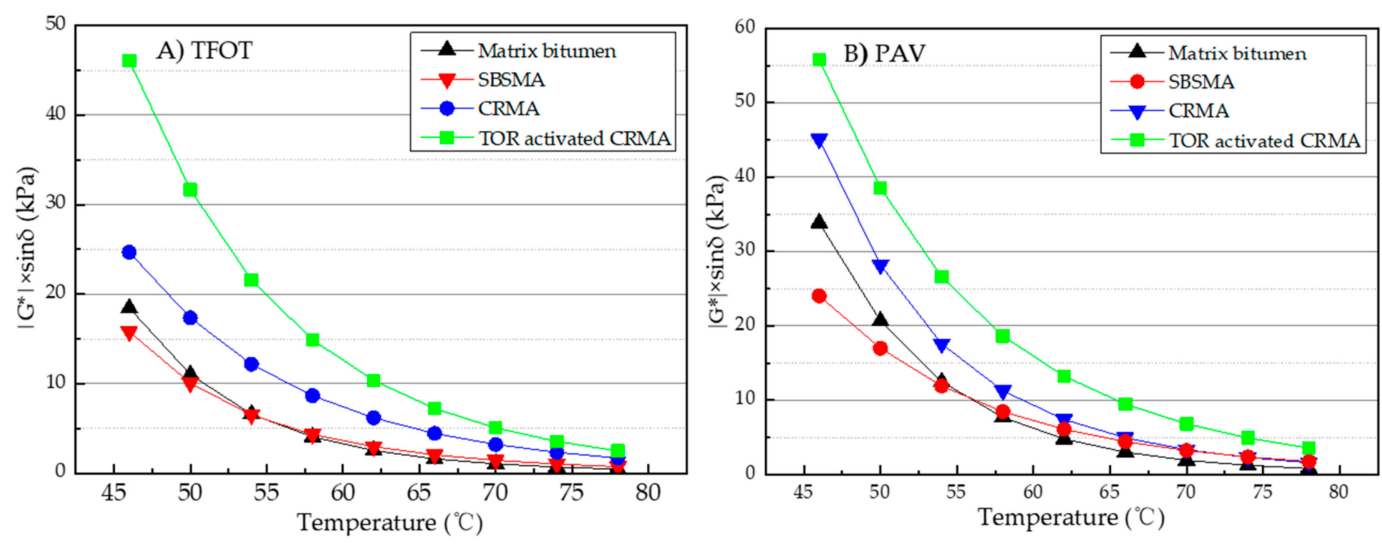

Figure 11. The fatigue factor of asphalt binder samples after aging. (A) thin film oven test (TFOT); (B) pressure aging vessel (PAV).

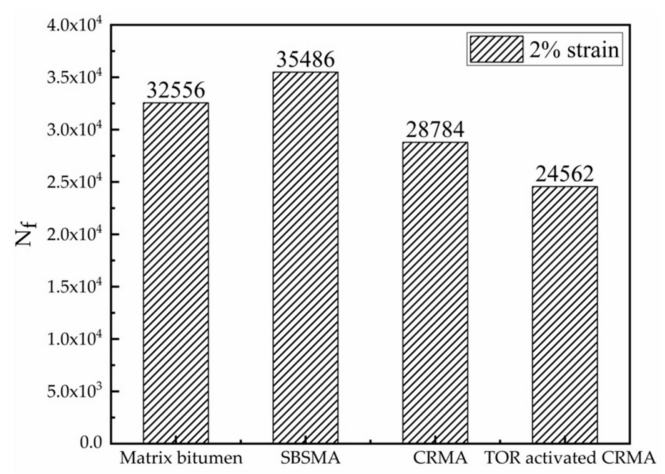

(a)

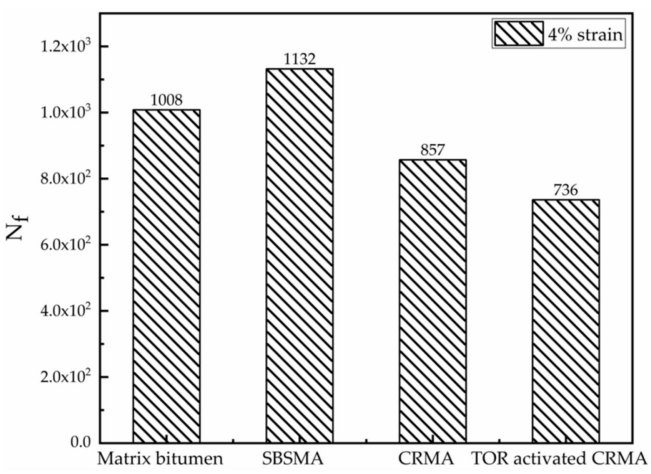

(b)

Figure 12. Fatigue life obtained using linear amplitude sweep (LAS) testing of asphalt binder at (a) $2 \%$ strain and (b) $4 \%$ strain level.

\section{Conclusions}

The article evaluated the viscoelasticity, rutting resistance, temperature sensitivity and fatigue resistance of TOR-activated CRMA by suitable rheological tests compared with CRMA, SBSMA and matrix bitumen. The experimental data obtained from this study led to the following conclusions:

The four samples are all heterogeneous systems; however, the degree of deviation was very different. In contrast, the degree of heterogeneousness of TOR-activated CRMA is significantly better than SBSMA and CRMA. This shows that TOR can effectively promote the compatibility between crumb rubber and asphalt binder.

TOR activators can drastically improve the viscoelastic behavior of CRMA at high temperatures. TOR-activated CRMA produced significant hardening both before and after aging. The deformation resistance of TOR-activated CRMA was preferable to that of SBSMA and CRMA.

In terms of high-temperature capability, TOR-activated CRMA has better high-temperature rutting resistance than the other three asphalt binders. However, the anti-rutting factor of four asphalt binders increases after aging, which is based on the aging and brittleness of the asphalt binder. Whether it was the original sample, long-term aging, or short-term aging, the maximum $\left|G^{*}\right| / \sin \delta$ of CRMA containing the TOR activator exhibited its preferred resistance to rutting.

The temperature sensitivity of SBSMA was greater than TOR-activated CRMA and CRMA for unaged samples. After PAV aging, the VTS of TOR-activated CRMA was smaller than the other three asphalt binders. However, it is only a tiny improvement in the temperature sensitivity of CRMA.

TOR active agent has a negative impact on the fatigue performance of CRMA. SBSMA exhibited superior fatigue resistance. The fatigue factor of the four asphalt binders, however, increased after 
aging, and the fatigue resistance decreased. The degree of SBSMA decline was the most obvious, and TOR-activated CRMA was more stable.

Compared with matrix bitumen, SBSMA, CRMA, TOR-activated CRMA has better compatibility, viscoelastic properties, and anti-rutting ability. However, the addition of the TOR active agent has a negative effect on the fatigue performance of CRMA.

Author Contributions: Data curation, Y.M., J.D., and C.L.; Formal analysis, J.D., C.L., and T.Y.; Investigation, F.M., Z.F., and T.Y.; Project administration, F.M.; Resources, F.M.; Writing—original draft, Y.M. and J.D.; Writing—review \& editing, Z.F. and M.J. All authors have read and agreed to the published version of the manuscript.

Funding: The project was supported by National Key R\&D Program of China (NO. 2018YFB1600200) and the Special Fund for Basic Scientific Research of Central Colleges, ChanG'an University (NO. 300102318208 and 300102210527).

Conflicts of Interest: The authors declare no conflict of interest.

\section{References}

1. Fu, Z.; Sun, Q.; Li, J. Preparation and performance characterization of asphalt sustained-release capsules. Int. J. Pavement Res. Technol. 2018, 11, 229-237. [CrossRef]

2. Gudipudi, P.P.; Underwood, B.S.; Zalghout, A. Impact of climate change on pavement structural performance in the United States. Transp. Res. Part D Transp. Environ. 2017, 57, 172-184. [CrossRef]

3. Ma, F.; Chao, Z. Road performance of asphalt binder modified with natural rock asphalt. Adv. Mater. Res. 2013, 634, 2729-2732. [CrossRef]

4. Yut, I.; Adam, Z. Correlation between rheology and chemical composition of aged polymer-modified asphalts. Constr. Build. Mater. 2014, 62, 109-117. [CrossRef]

5. Bernier, A.; Adam, Z.; Iliya, Y. Laboratory evaluation of rutting susceptibility of polymer-modified asphalt mixtures containing recycled pavements. Constr. Build. Mater. 2012, 31, 58-66. [CrossRef]

6. Kim, H.H.; Mazumder, M.; Lee, S.J.; Lee, M.S. Characterization of recycled crumb rubber modified binders containing wax warm additives. J. Traffic Transp. Eng. 2018, 5, 197-206. [CrossRef]

7. Bahia, H.U.; Davies, R. Effects of crumb rubber type and content on performance related properties of asphalt binders. In Proceedings of the Infrastructure: New Materials and Methods of Repair, San Diego, CA, USA, 13-16 November 1994; pp. 449-466.

8. Presti, D.L. Recycled tyre rubber modified bitumens for road asphalt mixtures: A literature review. Constr. Build. Mater. 2013, 49, 863-881. [CrossRef]

9. Moreno, F.; Sol, M.; Martín, J.; Pérez, M.; Rubio, M.C. The effect of crumb rubber modfier on the resistance of asphalt mixes to plastic deformation. Mater. Des. 2013, 47, 274-280. [CrossRef]

10. Phetcharat, S. Properties comparisons and cost analysis of asphaltic cement grade 80/100 and 60/70 modified with crumb rubber and SBS polymer. Adv. Mater. Res. 2014, 911, 484-488. [CrossRef]

11. Mannan, U.A.; Islam, M.; Weldegiorgis, M.; Tarefder, R. Experimental investigation on rheological properties of recycled asphalt pavement mastics. Appl. Rheol. 2015, 25, 1-9.

12. Girimath, S.; Singh, D.; Manthos, E.; Mampearachchi, W.K. Effects of reclaimed asphalt binder on rheological properties and cohesion energy of crumb rubber modified binder. Innov. Infrastruct. Solut. 2018, 3, 57. [CrossRef]

13. Girimath, S.; Singh, D.; Manthos, E.; Mampearachchi, W.K. Investigating the properties of crumb rubber modified bitumen using classic and shrp testing methods. Constr. Build. Mater. 2012, 26, 481-489.

14. Yadollahi, G.; Mollahosseini, H.S. Improving the performance of crumb rubber bitumen by means of poly phosphoric acid (PPA) and vestenamer additives. Constr. Build. Mater. 2011, 25, 3108-3116. [CrossRef]

15. Miró, R.; Martínez, A.H.; Moreno-Navarro, F.; del Carmen, R.-G.M. Effect of of ageing and temperature on the fatigue behaviour of bitumens. Mater. Des. 2015, 86, 129-137. [CrossRef]

16. Colbert, B.; You, Z. The properties of asphalt binder blended with variable quantities of recycled asphalt using short term and long term aging simulations. Constr. Build. Mater. 2012, 26, 552-557. [CrossRef]

17. Abdullah, M.E.; Kemas, A.Z.; Rosnawati, B.; Mohd, N.N.; Mohd, R.H. Short term and long term aging effects of asphalt binder modified with montmorillonite. Key Eng. Mater. 2013, 594, 996-1002. [CrossRef] 
18. Al-Khateeb, G.G.; Khalid, A.G. The combined effect of loading frequency, temperature, and stress level on the fatigue life of asphalt paving mixtures using the Idt test configuration. Int. J. Fatigue 2014, 59, $254-261$. [CrossRef]

19. Cui, Y.; Yu, Q.; Han, J.; Chen, C. Low temperature performance of rubber-modified asphalt under complex climate. Mater. Rev. 2018, 32, 2078-2084.

20. Das, S.; Murthy, V.S.R.; Murty, G.S. Particulate size effect on the rheology of sic-glass composites. J. Mater. Sci. 1999, 34, 1347-1352. [CrossRef]

21. Asli, H.; Ahmadinia, E.; Zargar, M.; Karim, M.R. Investigation on physical properties of waste cooking oil-rejuvenated bitumen binder. Constr. Build. Mater. 2012, 37, 398-405. [CrossRef]

22. Mohamed, M.; Mohamed, A.R.; Williams, R.C. Development of Non-Petroleum Based Binders for Use in Flexible Pavements; Final Report to Iowa Department of Transportation, TR-594; Iowa Department of Transportation: Ames, IA, USA, 2010.

23. Mandal, T.; Ryan, S.; Hussain, U.B.; Shayan, B. Effect of cross-linking agents on the rheological properties of polymer-modified bitumen. Road Mater. Pavement Des. 2015, 16, 349-361. [CrossRef]

24. Padhan, R.K.; Gupta, A.A.; Mohanta, C.S.; Badoni, R.P.; Bhatnagar, A.K. Performance improvement of a crumb rubber modified bitumen using polyoctenamer and cross linking agent. Road Mater. Pavement Des. 2016, 18, 999-1006. [CrossRef]

25. Puga, K.L.N.N. Rheology and Performance Evaluation of Polyoctenamer as Asphalt Rubber Modifier in Hot Mix Asphalt. Master's Thesis, Iowa State University, Ames, IA, USA, 2013.

26. Padhan, R.K.; Sreeram, A.; Gupta, A. Evaluation of trans-polyoctenamer and cross-linking agents on the performance of waste polystyrene modified asphalt. Road Mater. Pavement Des. 2020, 21, 1170-1182. [CrossRef]

27. Liang, M.; Ren, S.; Fan, W.; Wang, H.; Cui, W.; Zhao, P. Characterization of fume composition and rheological properties of asphalt with crumb rubber activated by microwave and TOR. Constr. Build. Mater. 2017, 154, 310-322. [CrossRef]

28. Peng, X.; Wu, M.; Zhou, X. Experiments on Rheological Properties of Tor Asphalt Rubber. J. Jiangsu Univ. 2010, 33, 440-444.

29. Kang, A.H.; Zhang, Q.; Li, P. Research on the influences of the molding processes of TOR asphalt rubber mixtures upon the pavement performance. Adv. Mater. Res. 2012, 535, 1819-1824. [CrossRef]

30. Liu, H.; Chen, Z.; Wang, W.; Wang, H.; Hao, P. Investigation of the rheological modification mechanism of crumb rubber modified asphalt (CRMA) containing TOR additive. Constr. Build. Mater. 2014, 6, 225-233. [CrossRef]

31. Liang, M.; Xin, X.; Fan, W.; Ren, S.; Shi, J.; Luo, H. Thermo-stability and aging performance of modified asphalt with crumb rubber activated by microwave and TOR. Mater. Des. 2017, 127, 84-96. [CrossRef]

32. Ma, F.; Dai, J.; Fu, Z.; Liu, J.; Dong, W.; Huang, Z. A new type of crumb rubber asphalt mixture: A dry process design and performance evaluation. Appl. Sci. 2020, 10, 372. [CrossRef]

33. Hao, G.; Huang, W.; Yuan, J.; Tang, N.; Xiao, F. Effect of aging on chemical and rheological properties of sbs modified asphalt with different compositions. Constr. Build. Mater. 2017, 156, 902-910. [CrossRef]

34. Wang, H.; You, Z.; Mills-Beale, J.; Hao, P. Laboratory evaluation on high temperature viscosity and low temperature stiffness of asphalt binder with high percent scrap tire rubber. Constr. Build. Mater. 2012, 26, 583-590. [CrossRef]

35. Wang, P.; Dong, Z.J.; Tan, Y.Q.; Liu, Z.Y. Effect of multi-walled carbon nanotubes on the performance of styrene-butadiene-styrene copolymer modified asphalt. Mater. Struct. 2017, 50, 17. [CrossRef]

36. Gao, J.; Wang, H.; Liu, C.; Ge, D.; You, Z.; Yu, M. High-temperature rheological behavior and fatigue performance of lignin modified asphalt binder. Constr. Build. Mater. 2020, 230, 117063. [CrossRef]

37. Kim, Y.; Lee, H.J.; Little, D.N.; Kim, Y.R.; Gibson, N.; King, G.; Pellinen, T.; Fee, F. A Simple Testing Method to Evaluate Fatigue Fracture and Damage Performance of Asphalt Mixtures. In Proceedings of the Association of Asphalt Paving Technologists-Proceedings of the Technical Sessions 2006 Annual Meeting, Savannah, GA, USA, 27-29 March 2006; pp. 755-788.

38. Sabouri, M.; Mirzaiyan, D.; Moniri, A. Effectiveness of linear amplitude sweep (Las) asphalt binder test in predicting asphalt mixtures fatigue performance. Constr. Build. Mater. 2018, 171, 281-290. [CrossRef]

39. Graessley, W.W. Linear viscoelasticity in entangling polymer systems. J. Chem. Phys. 1971, 54, 5143-5157. [CrossRef] 
40. Zhan, X.; Wang, D. Analysis of viscoelastic properties of modified asphalt via dynamic mechanical method. J. South China Univ. Technol. 2010, 38, 37.

41. Khonakdar, H.A.; Wagenknecht, U.; Jafari, S.H.; Hässler, R.; Eslami, H. Dynamic mechanical properties and morphology of polyethylene/ethylene vinyl acetate copolymer blends. Adv. Polym. Technol. 2010, 23, 307-315. [CrossRef] 